\title{
Initial approach to hypertension in the hemodynamics unit: review article
}

\author{
Abordagem inicial da hipertensão arterial sistêmica em unidade de hemodinâmica: \\ artigo de revisão \\ Gustavo Teixeira Fulton Schimit', José Manoel da Silva Silvestre², Wander Eduardo Sardinha², \\ Eduardo Durante Ramires², Domingos de Morais Filho², Guilon Otávio Santos Tenório', Fernando Barbosa Trevisan
}

\begin{abstract}
Correct identification and early management of hypertensive disorders should be a part of the therapeutic repertoire of every professional working in hemodynamics units. Based on recent publications, this study aims to propose a practical approach to the identification and early management of these disorders in this type of service.
\end{abstract}

Keywords: hypertension; blood pressure; therapeutics; antihypertensive agents.

\section{Resumo}

O reconhecimento correto e manejo inicial das síndromes hipertensivas devem fazer parte do arsenal terapêutico de todo profissional que trabalhe em unidade de hemodinâmica. Este trabalho tem por objetivo, baseado em publicações recentes, propor uma abordagem prática para identificação e manejo inicial destes agravos nessa unidade.

Palavras-chave: hipertensão; pressão arterial; terapêutica; anti-hipertensivos. 


\section{INTRODUCTION}

Constant technical advances in the profession, as well as in materials and new technologies, have contributed to the consolidation of the endovascular approach as a minimally invasive treatment. When carefully indicated and performed, clinical success rates are high, intervention times and hospitalizations are shorter and, consequently, morbidity and mortality are lower.

Ideally, endovascular procedures should be performed in hemodynamics units or in hybrid operating rooms, with competent multidisciplinary teams to optimize the care provided to patients, who often have multiple comorbidities. As patients are many times treated under local anesthesia and no anesthetist is present, the physician performing the intervention, often a vascular surgeon or a radiologist, should also make the diagnosis and treat several clinical conditions and complications, whether urgencies or emergencies.

Hypertension is one of these important disorders. Population surveys in Brazilian cities in the last 20 years showed that the prevalence of systemic hypertension is greater than $30 \%{ }^{1,2}$. Among patients aged 60 to 69 years, prevalence reaches $50 \%$ and, when patients are older than 70 years, it may reach $75 \%{ }^{1,2}$.

At some time in their lives, $1 \%$ of the patients with hypertension will have some hypertensive emergency ${ }^{3-5}$. Moreover, about $5 \%$ of the patients seen in urgency services have very elevated blood pressure levels, which, however, are not emergencies ${ }^{6}$.

However, despite the importance of this topic, a review of the literature showed that the clinical approach to hypertension as a complication during interventions in a cardiovascular unit has not been discussed. In several centers, protocols to manage such events are not homogeneous and have been developed according to empirical knowledge and the personal experience of each professional. This study reviewed recent publications to describe a practical approach for the identification and early management of urgencies and emergencies associated with hypertension in hemodynamics units.

\section{DEFINITIONS}

The correct definition of hypertensive syndromes and the accurate classification of each case are extremely important because they affect treatment.

Systemic hypertension is a multifactorial condition characterized by sustained elevated blood pressure levels ${ }^{7-10}$. The current threshold of $115 / 75 \mathrm{~mm} \mathrm{Hg}$ has been objectively adopted for the definition of normal blood pressure, and increases of 20/10 $\mathrm{mm} \mathrm{Hg}$ above this level double the risk of cardiovascular diseases ${ }^{11}$.

When blood pressure is elevated but does not increase, in the short term, the risk of cardiovascular disorders or end-organ damage, blood pressure is classified as markedly elevated. This definition includes patients with elevated blood pressure, usually systolic blood pressure above $120 \mathrm{~mm} \mathrm{Hg}$, without any history of end-organ damage.

Hypertensive urgencies are events of severe elevation of blood pressure without any evidence of end-organ damage in patients that had some previous lesion, such as acute myocardial infarction, stroke or heart failure ${ }^{11}$.

Hypertensive emergency is a severe elevation of blood pressure, usually above 180/120 $\mathrm{mm} \mathrm{Hg}$, and evidence of imminent end-organ damage ${ }^{11}$, requiring immediate measures to lower blood pressure, not necessarily down to normal values. The syndromes that define end-organ damage are: acute coronary syndrome ${ }^{12}$, encephalopathy, stroke, acute papilledema, acute pulmonary edema, aortic dissection, acute renal failure and eclampsia.

Another important definition is that of pseudohypertension, the elevation of blood pressure due to pain, discomfort, anxiety, interruption of continuous treatment, or any association of these factors ${ }^{13}$.

\section{STAGES OF THE PROCEDURE}

\section{Patient preparation}

Abiding by the Hippocratic Oath of doing no harm or maleficence to patients, the real need of an immediate intervention should be determined. That is, patients that are about to undergo elective procedures and have high blood pressure may perfectly wait for some days or weeks, so that better blood pressure control is achieved. However, this will hardly ever apply to patients with critical lesions, such as those that have to undergo lower limb salvage due to ischemia. However, even these patients should be sent to surgical treatment in their best possible clinical condition.

The best approach to these patients is an initial adequate preparation and objective analysis of clinical history ${ }^{14}$. Physical examination should focus on the vascular system, and special attention should be paid to the access site. Depending on their comorbidities, patients should be examined by a cardiologist, laboratory tests should be evaluated and surgical risk should be defined ${ }^{15}$. 
Patients should be well hydrated and should have received antiplatelet therapy. Any history of allergy to contrast medium should be investigated, and oral glucose-lowering drugs, such as metformin, should be discontinued, if necessary ${ }^{16}$.

The patient should have fasted for 8 hours. Preanesthetic medication may be used before the patient is taken to the operating room. Medications such as $7.5 \mathrm{mg}$ to $15 \mathrm{mg}$ sublingual midazolam, defined according to patient age, may help to reduce anxiety and prevent pseudohypertension ${ }^{16}$.

\section{During the procedure}

Based on the principle that the procedure should be performed with the patient under local anesthesia and that there will be no participation of an anesthetist, anesthesia should be achieved with $1 \%$ lidocaine and no vasoconstrictor ${ }^{16}$. For longer procedures, $0.25 \%$ bupivacaine is an attractive option.

An avoidable cause of blood pressure elevation during the procedure is pain, which may range from the discomfort inherent to the procedure to intense ischemic pain in lower limbs in association with trophic lesions. Therefore, adequate pain control is very important and should be performed cautiously, at small gradual increases if necessary. The drugs most often used are IV morphine ( 2 to 4 mg every 5 to 10 minutes) ${ }^{13}$ or fentanyl (initial dose of 25 to $50 \mu \mathrm{g})$. In complex cases and long procedures, or in case of pain refractory to potent painkillers, spinal or continuous epidural block may be necessary ${ }^{16}$. In all cases, the patient should receive supplemental oxygen, and noninvasive monitoring should be constant.

\section{Initial management of hypertension}

When elevated blood pressure is detected, the first step is to determine whether the patient runs the risk of an imminent cardiovascular event and to rule out hypertensive urgencies and emergencies.

\section{Markedly elevated blood pressure}

In patients without a history of cardiovascular disorders, treatment should aim at the underlying cause of blood pressure elevation, using painkillers and anti-anxiety drugs. The value read during blood pressure measurement should never be treated in isolation, as there is the risk of severe iatrogenic complications. In general, no anti-hypertension drugs are necessary ${ }^{13}$. However, if there is no adequate response to painkillers and conscious sedation, and considering the reduction of bleeding at the puncture site, the antihypertensive drug that the patient routinely takes may be used ${ }^{15}$.

\section{Hypertensive urgencies}

Patients with a history of cardiovascular impairment, such as chronic coronary disease, heart failure, aortic aneurysm or previous stroke, should be included in the group of hypertensive urgencies. Treatment should be initiated as soon as the diagnosis is made to reduce mean blood pressure in $25 \%$ and control it in up to 24 to 48 hours $^{17}$.

Drugs should be administered orally, and the ones most often used, together with their doses and main characteristics, are listed below ${ }^{13,17}$.

Captopril $^{13,17}$ : an angiotensin-converting enzyme inhibitor. It should be administered in a dose of $6.25 \mathrm{mg}$ to $25 \mathrm{mg}$, which may be repeated every 1 to 2 hours. Its effect begins in 15 to 30 minutes and reaches its maximum in one hour. It is efficacious and well tolerated by patients. Its use is more appropriate for patients with congestive heart failure, but should be avoided in patients with bilateral renovascular disease.

Clonidine $^{13,17}$ : central alpha-2 adrenergic agonist. Its effect begins in 30 to 60 minutes and reaches its maximum in 2 to 4 hours. The dose is 0.1 to $0.2 \mathrm{mg}$. An initial dose of $0.2 \mathrm{mg}$ is recommended, followed by an additional $0.1 \mathrm{mg}$ every hour until blood pressure is under control. Maximum recommended dose is $0.6 \mathrm{mg}$. It is well tolerated by patients.

Propranolol ${ }^{13,17}$ : beta-blocker most often used in urgencies. Its effect begins in one hour and reaches its maximum in 2 to 4 hours. The recommended dose is 10 to $80 \mathrm{mg}$, which may be repeated every 4 hours. This drug should be avoided in patients with chronic pulmonary disease because of the possibility of bronchospasm and in patients with atrioventricular block.

Diuretics ${ }^{13,17}$ : the most common are loop diuretics, such as furosemide. They are indicated in cases associated with heart failure, or when vasodilators are being used and there is sodium and fluid retention. The dose is $40 \mathrm{mg}$, which should be increased as necessary.

Minoxidil ${ }^{13,17}$ : direct action in vascular muscles for vasodilation. It is indicated in cases of resistant hypertension in patients taking other classes of medication. Its effect begins in 30 minutes to 2 hours and reaches its maximum in 2 to 4 hours. The recommended dose is 5 to $10 \mathrm{mg}$, which may be repeated every 4 hours. Secondary effects are tachycardia and water and sodium retention, and should, therefore, be avoided in patients with heart 
disease. For the same reason, its association with loop diuretics and beta-blockers is recommended.

Regardless of what procedure is performed, some patients will need hospitalization to receive adequate treatment. They should not be discharged before blood pressure has been under control for at least 6 hours, and should be scheduled for early outpatient review in 2 to 3 days $^{18,19}$.

\section{Hypertensive emergencies}

In patients with clinical signs or symptoms suggestive of end-organ damage, with intense dyspnea, acute pulmonary edema, paleness, sweating, altered consciousness or focal signs, the planned procedure should be cancelled due to the imminent risk of death. Cardiovascular operating room have full support for patients in serious conditions, and, therefore, initial care is the responsibility of the attending physician and should be provided as soon and as efficiently as possible, following preestablished protocols and primary and secondary $\mathrm{ABCD}^{13,17}$

Therefore, treatment should begin immediately in these cases, together with clinical assessment, and should be complemented with parenteral administration of anti-hypertensive drugs. In minutes to one hour, blood pressure should have a reduction of $20 \%$ to $25 \%$ of mean initial value at the most. Blood pressure should be measured constantly, preferably using an invasive method, and oral medication should be started as soon as the desired blood pressure is reached.

Individualized treatment of each case of hypertensive emergency goes beyond the objective of this study, whose purpose is to provide initial guidelines for the management of these patients until the time when they are transferred to the emergency room or the intensive care unit. However, as already stated above, treatment should be initiated immediately. All medication should be administered parenterally, and the drugs most often used by most professionals and widely available in the market are listed below and summarized in Table 1, together with their doses and main characteristics ${ }^{13,17}$.

Nitroprusside sodium ${ }^{13,17}$ : arterial and venous vasodilator that may be used in peripheral or central vein. Its effect begins immediately (less than 1 minute) and lasts 3 to 5 minutes, which is the reason why it should be administered in continuous infusion. Also, it should be protected from light because it is photosensitive. Initial recommended dose is $0.3 \mu \mathrm{g} / \mathrm{kg} / \mathrm{min}$.

In practical terms, the contents of a vial $(50 \mathrm{mg})$ should be diluted in $250 \mathrm{~mL}$ saline solution and administered at $3 \mathrm{~mL} / \mathrm{h}$. Every 1 to 2 minutes, blood pressure should be measured again and, if necessary, the dose should be increased 1 to $2 \mathrm{~mL} / \mathrm{h}$. Maximum or maintenance dose should be 5 to $10 \mu \mathrm{g} / \mathrm{kg} / \mathrm{min}$.

It is a very effective drug for the treatment of hypertensive emergencies. However, nitroglycerin should be preferred in case of patients with acute coronary syndrome.

Blood pressure and the level of consciousness should be evaluated frequently in neurological emergencies. In such cases, intracranial vasodilation may elevate intracranial pressure, which may reduce cerebral perfusion pressure when associated with a decrease in mean blood pressure.

On rare occasions, it may lead to intoxication by cyanide, which is the reason why it should be avoided or used cautiously in patients with kidney or

Table 1. Parenteral anti-hypertensive drugs.

\begin{tabular}{|c|c|c|c|c|c|c|c|}
\hline Medication & Mechanism & Initial dose & $\begin{array}{l}\text { Effect } \\
\text { begins }\end{array}$ & Maximum dose & Lasts & Contraindications & Adverse effects \\
\hline Nitroprusside & $\begin{array}{l}\text { Arterial and ve- } \\
\text { nous vasodilator }\end{array}$ & $0.3 \mu \mathrm{g} / \mathrm{kg} / \mathrm{min}$ & $\begin{array}{l}\text { Less than } \\
1 \text { minute }\end{array}$ & 5 to $10 \mu \mathrm{g} / \mathrm{kg} / \mathrm{min}$ & $\begin{array}{l}3 \text { to } 5 \\
\text { minutes }\end{array}$ & $\begin{array}{l}\text { Relative: Kidney and } \\
\text { liver failure }\end{array}$ & $\begin{array}{l}\text { Toxicity by } \\
\text { cyanide }\end{array}$ \\
\hline Nitroglycerin & $\begin{array}{l}\text { Primarily venous } \\
\text { vasodilator }\end{array}$ & 5 to $10 \mu \mathrm{g} / \mathrm{kg} / \mathrm{min}$ & $\begin{array}{l}2 \text { to } 5 \\
\text { minutes }\end{array}$ & $100-200 \mu \mathrm{g} / \mathrm{kg} / \mathrm{min}$ & $\begin{array}{l}3 \text { to } 10 \\
\text { minutes }\end{array}$ & - & Headache \\
\hline Metoprolol & Beta-blocker & $5 \mathrm{mg}$ in 5 minutes & $\begin{array}{l}5 \text { to } 10 \\
\text { minutes }\end{array}$ & $15-20 \mathrm{mg}$ & hours & $\begin{array}{l}\text { 2nd and 3rd degree } \\
\text { AVB, severe HF, } \\
\text { asthma }\end{array}$ & $\begin{array}{l}\text { Bradycardia, } \\
\text { TAVB, bron- } \\
\text { chospasm }\end{array}$ \\
\hline Propranolol & Beta-blocker & $1 \mathrm{mg}$ in 5 minutes & $\begin{array}{l}5 \text { to } 10 \\
\text { minutes }\end{array}$ & $6-8 \mathrm{mg}$ & hours & $\begin{array}{l}\text { 2nd and 3rd degree } \\
\text { AVB, severe HF, } \\
\text { asthma }\end{array}$ & $\begin{array}{l}\text { Bradycardia, } \\
\text { TAVB, bron- } \\
\text { chospasm }\end{array}$ \\
\hline Labetalol & $\begin{array}{l}\text { Alpha- and beta- } \\
\text { blocker }\end{array}$ & $\begin{array}{l}10-20 \mathrm{mg} \text { in } 10 \\
\text { minutes }\end{array}$ & $\begin{array}{l}5 \mathrm{~min}- \\
\text { utes }\end{array}$ & $300 \mathrm{mg}$ & 4 to $8 \mathrm{~h}$ & $\begin{array}{l}\text { 2nd and 3rd degree } \\
\text { AVB, severe HF, } \\
\text { asthma }\end{array}$ & $\begin{array}{l}\text { Bradycardia, } \\
\text { TAVB, bron- } \\
\text { chospasm }\end{array}$ \\
\hline
\end{tabular}

Olmos RD et al. $.^{13} . A V B=$ atrioventricular blocker; $\mathrm{HF}=$ heart failure; TAVB = total atrioventricular block. 
liver diseases. Symptoms include metabolic acidosis, confusion and headache.

Nitroglycerin ${ }^{13,17}$ : direct vasodilator that acts upon the smooth muscles of vessels, particularly veins. It may be used in peripheral or central veins. It is indicated primarily when the patient has acute pulmonary edema or acute coronary syndrome. Its main collateral effect is headache and, in practical terms, it has no contraindications.

Its effect begins 2 to 5 minutes and lasts 3 to 10 minutes, and it should be administered in continuous infusion. Initial recommended dose is 5 to $10 \mu \mathrm{g} / \mathrm{kg} / \mathrm{min}$.

In practical terms, the contents of a vial $(50 \mathrm{mg})$ should be diluted in $250 \mathrm{~mL}$ saline solution and administered at $3 \mathrm{~mL} / \mathrm{h}$. Every 5 minutes, blood pressure should be measured again and, if necessary, the dose should be increased 1 to $2 \mathrm{~mL} / \mathrm{h}$. Maintenance dose should be 100 to $200 \mu \mathrm{g} / \mathrm{kg} / \mathrm{min}$.

As its vasodilating effect is not as powerful as that of nitroprusside, these two drugs should be combined when blood pressure is not controlled adequately.

Beta-blockers ${ }^{13,17}$ : specially indicated when the major concern is to reduce heart rate, such as when signs and symptoms are suggestive of acute aortic dissection.

It should be administered without dilution, as slow bolus over 5 minutes, a dose that may be repeated up to 3 times or after the desired heart rate is achieved.

They are contraindicated for patients with uncontrolled heart failure, with elevated risk of bronchospasm, or patients with second or third degree atrioventricular block.

The main drugs available in the market are metoprolol and propranolol. Their recommended doses and main characteristics are:

Metoprolol: dose of $5 \mathrm{mg}$ in 5 minutes. Its effect begins in 5 to 10 minutes, and the dose should not exceed 15 to $20 \mathrm{mg}$.

Propranolol: dose of $1 \mathrm{mg}$ in 5 minutes. Its effect begins in 5 to 10 minutes, and the dose should not exceed 6 to $8 \mathrm{mg}$.

Labetalol $^{13,17}$ : alpha and beta-adrenergic receptor blocker. The initial recommended dose is 10 to $20 \mathrm{mg}$ in 10 minutes. Doses of 10 to $20 \mathrm{mg}$ may be repeated every 10 minutes, and the maximum dose should not exceed $300 \mathrm{mg}$. However, its cost is very high and it may not be available in all emergency rooms.

After initial measures, primary and secondary $\mathrm{ABCD}$, optimization of drug therapy and adequate complementary investigations, the patient can be sent to the emergency room or the intensive care unit to be treated by a multidisciplinary team.

\section{CONCLUSION}

Among patients seen in a hemodynamics unit, hypertension is a common disorder. The capacity to identify it and, above all, its correct management are the responsibility of the physicians in the unit. Therefore, they should be prepared to recognize hypertensive urgencies and emergencies immediately and not only and simply treat the value read in the blood pressure monitor. Their preparation will prevent severe iatrogenic events and will ensure that their patients receive safe and high-quality medical care.

\section{REFERENCES}

1. Cesarino CB, Cipullo JP, Martin JFV, et al. Prevalência e fatores sociodemográficos em hipertensos de São José do Rio Preto. Arq Bras Card. 2008;91(1):31-35. http://dx.doi.org/10.1590/ S0066-782X2008001300005

2. Rosário TM, Scala LCNS, França GVA, Pereira MRG, Jardim PCBV. Prevalência, controle e tratamento da hipertensão arterial sistêmica em Nobres, MT. Arq Bras Card. 2009;93(6):672-678. http://dx.doi.org/10.1590/S0066-782X2009001200018

3. Aggarwal $M$, Khan IA. Hypertensive crises: hypertensive emergencies and urgencies. Cardiology clinics. 2006;24:135-46. http://dx.doi.org/10.1016/j.ccl.2005.09.002

4. Marik PE, Varon J. Hypertensive crises: challenges and management. Chest. 2007;131:1949-62. http://dx.doi.org/10.1378/chest.06-2490

5. Zampaglione B, Pascale C, Marchisio $M$, et al. Hypertensive urgencies and emergencies: prevalence and clinical presentations. Hypertension. 1996;27:144-47. http://dx.doi.org/10.1161/01. HYP.27.1.144

6. Karras DJ, Ufberg JW, Harrigan RA, et al. Lack of relationship between hypertension-associated symptoms and blood pressure in hypertensive ED patients. Am J Emerg Med. 2005;23:106-10. http://dx.doi.org/10.1016/j.ajem.2004.02.043

7. Sociedade Brasileira de Cardiologia. V Diretrizes Brasileiras de Hipertensão. Arq Bras Cardiol. 2006 Fev: 1-48.

8. Malta DC, Moura L, Souza FM, Rocha FM, Fernandes FM. Doenças crônicas não-transmissíveis: mortalidade e fatores de risco no Brasil, 1990 a 2006 in Saúde Brasil 2008. Brasília: Ministério da Saúde; 2009. p. 337-362.

9. Banco Mundial. Enfrentando o desafio das doenças nãotransmissíveis no Brasil. Banco Mundial; 15 Nov 2005. Documento. Relatório n. 32576-BR.

10. Williams B. The year in hypertension. JACC. 2010;55(1):66-73.

11. National Heart, lung, and Blood Institute. Seventh report of the Joint National Committee on prevention, detection, evaluation, and treatment of high blood pressure (JNC-7) 2003. Bethesda: $\mathrm{NIH}$; 2003. Publication n. NIH 03-5233.

12. Stewart DL, Feinstein SE, Colgan R. Hypertensive urgencies and emergencies. Prim Care. 2006;33:613-23. http://dx.doi. org/10.1016/j.pop.2006.06.001

13. Olmos RD, Martins HS. Hipertensão arterial sistêmica: abordagem inicial. In: Martins HS, Brandão Neto RA, Scalabrini Neto A Velasco IT, organizadores. Emergências clínicas. 6. ed. Barueri: Editora Manole; 2011. p. 303-16.

14. Kaufman J, Lee Michael. Vascular \& interventional radiology. Philadelphia: Mobsy, 2004. 
15. Guimarães M, Uflacker R. Tratamento endovascular - fundamentos e técnicas básicas. In: Brito C). Cirurgia Vascular - Cirurgia Endovascular - Angiologia. Rio de Janeiro: Revinter; 2008. p. $1195-224$.

16. Fonseca Filho VL, Loureiro E. Doença oclusiva femorpoplítea. In: Lobato AC. Cirurgia Endovascular. 2. ed. São Paulo: ICVESP; 2010. p. 961-78.

17. Feitosa Filho GS, Giorgi DMA. Hipertensão no pronto socorro. In: Martins HS, Damasceno MCT, Awada SB. Pronto socorro: diagnostico e tratamento em emergências. 2. ed. Baruei: Editora Manole; 2008. p. 387-96.

18. Izzo JL, Sica DA, Black HR. Hypertension Primer: The Es- sentials of High Blood Pressure Basic Science, Population Science and Clinical Management. Philadelphia: Williams \& Wilkins; 2008. p. 489-93.

19. Kaplan NM. Hypertensive Crises. In: Kaplan NM. Clinical Hypertension. 9th ed. Philadelphia: Williams \& Wilkins; 2006. p. $311-24$.

\section{Correspondence}

Gustavo Teixeira Fulton Schimit Av. Presidente Castelo Branco, 469 - Jardim Presidente CEP 86061-335, Londrina (PR), Brazil E-mail: gustavo.vascular@gmail.com

Author information GTFS is a resident physician (Angioradiology and Endovascular Surgery) at Hospital Universitário Regional do Norte do Paraná.
JMSS is an associate professor of Angiology and Vascular Surgery at the Department of Surgical Practice of Universidade Estadual de Londrina (UEL)

WES is an adjunct professor of Angiology and Vascular Surgery at the Department of Surgical Practice of Universidade Estadual de Londrina (UEL)

EDR is an assistant professor of Angiology and Vascular Surgery at the Department of Surgical Practice of Universidade Estadual de Londrina (UEL)

DMF is an adjunct professor of Angiology and Vascular Surgery at the Department of Surgical Practice of Universidade Estadual de Londrina (UEL).

GOST is a resident physician (Vascular Surgery) at Hospital Universitário Regional do Norte do Paraná FBT is a resident physician (Vascular Surgery) at Hospital Universitário Regional do Norte do Paraná.

Author's contribution Conception and design: GTFS, JMSS Analysis and interpretation: GTFS, JMSS, WES, EDR, DMF, GOST, FBT Data collection: GTFS, JMSS, WES, EDR, DMF, GOST, FBT Writing the article: GTFS, IMSS Critical revision of the article: GTFS, JMSS

Final approval of the article*: GTFS, JMSS, WES, EDR, DMF, GOST, FBT Statistical analysis: GTFS, JMSS Overall responsibility: GTFS, JMSS Funding information: GTFS, JMSS

*All authors should have read and approved of the final version of the article submitted to I Vasc Bras. 